\title{
Diversity Management in Sustainable Human Resources Management
}

\author{
Viera Sukalova ${ }^{1, *}$, Pavel Ceniga ${ }^{2}$ \\ ${ }^{1}$ University of Žilina, Univerzitna 1, 01026 Zilina, Slovakia \\ ${ }^{2}$ University of Žilina, Univerzitna 1, 01026 Zilina, Slovakia
}

\begin{abstract}
Today, globalization is becoming more and more widespread and important in almost all areas - in the social, economic and political spheres. In most cases, it is globalization that brings diversity to everyday life. This diversity is gradually penetrating into other spheres, which is why business managers are increasingly confronted with a diverse workforce; employees of different origins, race, gender, or age. The policy of diversity management contributes to the strengthening of social responsibility of the company and is also an element of the competitiveness. Our research was aimed to enhance understanding of diversity management importance in nowadays organization, to explain various aspects of management diversity, it's legislative framework. Another objective was to examine perception of the issue of management diversity by the middle managers of various organisations in Slovakia. To achieve these goals we used methods of literature review, desk review; primary data were collected by questionnaire and interview. Finding show the relation between demographic development and diversity management in companies; in examining the perception of the issue of diversity management, we found the understanding of diversity management as synonymous with anti-discrimination measures. Our research led also to recommendations for implementation of management diversity for human resource management sustainability.
\end{abstract}

\section{Introduction}

The economic, political and, finally, technological environment has changed significantly both nationally and internationally. Among the most important challenges that affect current developments in the economic environment, as mentioned above, in particular globalization, the knowledge economy and demographic changes. All these impacts have their own impacts on human resources management. HR department is the most important department in any organization because it deals with human resources which are the most important, valuable and appreciable asset of any organization. [1]Today, globalization is becoming increasingly widespread and important in almost all areas - in the social, economic and political spheres. In most cases, it is globalization that brings diversity into everyday life. This diversity is gradually spreading to other spheres, and therefore

*Corresponding author: sukalova@fpedas.uniza. 
business managers are increasingly encountering a diverse workforce, i.e. employees of different origins, race, sex or age. Diversity management, or in other words, diversity management, is a management concept that affects the entire organizational culture in society. It can also be defined as voluntary activities in a company that serve to better involve employees coming from different backgrounds and backgrounds from formal and informal organizational structures using intentional programs and methods. [2] In most companies, diversity and the integration of its management into the organization is becoming a common reality. Increasing diversity of the workforce, speed of development of new technologies, increasing demand for the practice of Corporate Social Responsibility (CSR) - all these are undeniable triggers of the need to take measures to manage everincreasing diversity. [3] Slovakia's lagging behind in creating a diverse environment compared to developed European countries is also related to the situation in other areas of economic and social development. Among other things, the consequences of discrimination in the labour market, particularly among women, ethnic groups, young and older people, are long-term unemployment, loss of working habits and social exclusion. The group of $50+$ year's employees is also described in Slovak legislation as disadvantaged groups on the labour market and also young people (graduates). [4] They more often fill labour market statistics and appear as a significant group among the long-term unemployed. Statistics on the position of women in the labour market highlight several specificities. For example, women work part-time more often and start much less business than men. Women also stay longer out of work than men. Monitoring the development of indicators of employment, unemployment and wage conditions shows in more detail discriminated groups, the degree of their integration in the labour market and the possibilities of increasing the diversification of workers in the labour market. In terms of the openness of the labour market, or in other words, in terms of the diversity of nationalities working in the Slovak Republic, we must state that the labour market is open to foreigners. The main reason is administrative barriers, when work permits are issued by labour offices only after proving the impossibility to fill such a job with citizens of Slovak nationality. In general, there are many reasons to include diversity management in the day-to-day running of an organization. One reason is that diversity will never disappear from the workplace; on the contrary, employees will become more and more diverse over time. Another reason is the moral responsibility of the company to provide all workers with the same conditions and opportunities. [2] The last argument is the competitive advantage of the organization by gaining a competitive advantage by exploiting the uniqueness of its employees.

\section{Research Methodology}

The aim of our research was to analyse the circumstances and development of management diversity and to specify current issues of management diversity in Slovakia as well as to determine the perception of this issue by middle managers of various organizations. The methodology of research includes: literature review (to investigate the evolution of diversity management concept); desk review (to analyse secondary data, to research the latest theoretical and practical developments in management). Primary data were collected by questionnaire and semi - structured interview. However, there are significant gaps in the knowledge of multiculturalism and migration in Slovakia, moreover, the public debate on this subject is weak, simplistic and often burdened with negative prejudices and preadopted schemes. In our research in 2018 - 2019 focused on the perception of the problems of management diversity in the form of a questionnaire and interview on a sample of 329 middle managers from various organizations. 


\section{The development and legal aspects of the diversity management}

Last decades, diversity has come to play a central role in organizational life, due to increased globalization, greater workforce diversity, and the increasing complexity of jobs. [5] These changes require us to adopt new lenses to fully understand the dynamics that impact international human resource management policies and practices. [6] The term diversity has many interpretations. Different scholars have defined it in different way.

\subsection{Definition of the term}

For further investigation it is necessary to define the notion of diversity, so we give some definitions. Diversity as a concept and solution to the new labour market situation in the 20th century was brought by William Johnston and his team in Workforce 2000. [7] He anticipated an increase in the demands on industrial workers, a slowing population growth and a high share of older people, women and people with disabilities in the labour market. Cox (2001) defined diversity as the variation of social and cultural identities among people existing together in a defined employment or marketing setting while William and O'Reilly (1998) defined diversity as the degree of heterogeneity among team members on specified demographic dimensions, their theory aims to explain how such heterogeneity affects team processes and performance. [5, 8] Harrison and Klein (2007) specified diversity - which they defined as "the distribution of differences among the members of a unit with respect to a common attribute" (p. 1200) - as three distinct concepts: separation, variety, and disparity. Whereas separation and disparity measure horizontal and vertical differences, respectively, variety captures within-unit diversity of categorical data. [9] In a European context, diversity sources are defined in terms of gender, age, race and ethnicity, sexual orientation, religion and belief, disability. Diversity management can influence the management quality in organization and the sustainability. Findings show that there is a significant positive relationship between workforce quality and organizational performance as well as management quality and organizational performance. [10]

\subsection{Diversity management development}

Diversity Management, known as "Diversity Management", has its origins in the US, where its introduction in businesses in the 20th century was the result of many equality movements. In America, at that time, it was mainly fighting for equality of people based on their ethnic origin and gender. The first response to the equality movement was various anti-discrimination laws dealing with gender equality in terms of gender, skin colour and nationality in the workplace. The development of diversity management in Europe can be attributed to the existence of international businesses. Initially, cultural diversity was seen as a threat by managers because they considered best management practices to be those that were identical in all foreign branches. [11] With the expansion of US corporate affiliates, diversity management eventually got to Europe as these affiliates also transferred their management practices. The theoretical literature on diversity in organizations can be divided into a positive and a negative perspective. [5] The positive perspective mainly draws on theories of information and decision making that highlights the benefits of differential information resources. Different ethnic backgrounds, for example, may provide different distributions of skills and knowledge. The negative perspective draws on the 
theories of social categorization. [12] Cultural diversity is what binds all groups of employees at all levels in a company. Cultural diversity calls for a type of organizational culture where all members can pursue their aspirations without being inhibited by gender, race, nationality or other qualities that are irrelevant to performance. [13] These theories suggest that diversity nurtures conflict and turnover and decreases social identification, cohesion, and performance. Given the contrasting theories, the overall effect of increasing demographic diversity is unclear. Diversity can also be defined as diversity, inequality, difference and individuality, which arises through numerous differences between people. When it comes to the working environment, diversity is mainly defined by the diversity of individual abilities, experience, competencies and qualifications of individual workers. [14] In the business sector, diversity is used in the sense of "corporate management". It applies mainly to large, multinational companies. At the level of economic and social enterprise policy, diversity as diversity management is supported by the implicit main idea: the world is diverse and countries need to emphasize the importance of diversity management to develop innovation and competitiveness in the global market. If we look at the context that supported the importance of diversity management in Western Europe, we would find that organizational structures had to respond to the phenomena such as increased demographic complexity, internal migration and more women in the labour market. The reasons for introducing diversity policies, programs and measures in the workplace are legal, ethical and especially economic. The most common real or expected benefits of diversity are recruiting and maintaining a quality workforce; enhancing the reputation and image of the business and its position within local communities; innovation leading to new products and services and new markets. By promoting diversity, companies are quite consciously striving to increase profits, customer satisfaction and their corporate image. Diversity management in a corporate environment can be approached through a variety of approaches. The first is a restrictive perspective emphasizing the legislative aspect of equal opportunities by perceiving diversity management as a duty. Another more interesting point of view is the vision of productivity growth and the potential of the opportunities that diversity management offers. The issue is also related to how to attract the market and how to reach a much wider and so far neglected group of customers. It is an investment-based approach that brings many expectations. The third area is the concept of Corporate Social Responsibility (CSR). The policy of equal opportunities for men and women is one of the concrete ways in which the CSR concept can be fulfilled in an organization. The company's vision and basic values are reflected primarily in the corporate culture and in the values of the entire company. $[15,16]$

\subsection{Legal context of the diversity management}

The concept of diversity management is based on the assumption that diversity of employees has a positive impact on the company's economic results and overall working climate. At the same time, the existence of good diversity management is one of the manifestations of respect for the legislation governing the obligation to respect the principle of equal treatment. Equality of opportunity is currently an official and respected public policy agenda, and at the same time a declared common value and an accompanying condition for the EU to achieve its objectives of growth, employment and social cohesion. Anti-discrimination for whatever reason is a paradigm and a fundamental principle of the new Europe. In recent years, the European Commission has intensified the fight against discrimination in industrial relations. It is undisputed that legislation has become a decisive factor in remedying discriminatory practices. Anti-discrimination law is part of the legislation of the Slovak Republic. The carrier and a basic regulation governing the principle of equal treatment in the exercise of such powers dependent work is the 
Constitution of the Slovak Republic. In the area of industrial relations is key legislation regulating the area the Labour Code, the Anti-Discrimination Act and other regulations regulate similar employment relationship The Labour Code guarantees women and men the right to equal treatment if: these are access to employment, remuneration and workflow, vocational training and working conditions. The right to equal treatment shall apply to employees, as well as jobseekers. Discrimination of employees on grounds of labour law is prohibited in industrial relations gender, marital and family status, sexual orientation, race, skin colour, language, age, adverse medical condition or disability, genetic characteristics, faith, religion, political or other thinking, trade union activity, national or social origin, belonging to a nationality or ethnic group, property, gender, or other status, or because of a crime or otherwise anti-social activities. [17] Despite the fact that the current Slovak antidiscrimination legislation has been reacted a protection framework that complies with the requirements of the anti - discrimination directives, the application framework practice still highlights the need to make protection against discrimination more effective. The application of the concept of management diversity may also contribute to this.

\section{Results and discussion}

Along with globalization, the application of diversity management has become an indispensable necessity and also an opportunity to improve the situation in Slovak companies.

\subsection{Demographic aspects of diversity at work}

In recent years there have been significant demographic changes also in Slovakia, mainly due to the aging population and the related pension system crisis. It is necessary to revitalize the labor market through better integration of previously neglected workforce: women with young children, disabled citizens, elderly people or vice versa without work experience reserves. Demographic change themes relate to the changing nature of the concept of the workforce, especially in our local conditions on age and population aging (age management), gender (Gender), and ethnic minorities, which are likely to create ever larger part of the workforce. The changing demographic situation will affect both organizations and society as a whole. A typical example is currently scarce workers professions, where companies are increasingly reaching out to foreign operators. The integration of foreigners into Slovak teams, their training and leadership then requires thorough preparation - in order to eliminate language and cultural barriers. Not only an interpreter is enough, internal trainers or leaders who have been able to train foreigners in their language and also act as "cultural bridges" have proven themselves. On the contrary, internal "isolation" of foreign teams without their actual involvement in the company structure creates unhealthy relationships, sometimes tensions, that certainly do not testify to the company's performance.

\subsection{Slovak specifics and diversity management perception}

Thus, from a business perspective, diversity is important to counteracting adverse demographic trends. Despite the current low unemployment rate, companies are addressing the problems of staff shortages, because every person who wants to work is already working, leaving vacant jobs. Voluntary unemployed people prefer to study, care for their child or receive social support from the state to work. If, in theory, all unemployed 
occupied vacancies, unemployment would fall below four percent. In practice, however, this is not possible because tens of thousands of jobseekers do not have the skills and competences required by the job profile and the requirements of companies. Companies are trying to solve the situation mainly by increasing work efficiency and employing people from disadvantaged groups. The next step is retraining, which in 2018 passed approximately 60000 domestic job seekers. Some companies have started to employ also foreigners. We can say, that firstly, main areas in terms of different groups of employees are at issues of certain social groups in terms of diversity management (employment of persons over 50 years of age, disabled people, foreigners, equal treatment of men and women in the organization, mothers and fathers on parental / maternity / paternity leave). Second part is employment of foreigners (what specific activities the organization carries out, number of foreigners employed, structure of employed foreigners in terms of: country of origin, age, gender, position held, motivation of employers to employ foreigners, activities in relation to employed foreigners). Many sectors have problems with qualified employees; for example IT companies, carmakers and their suppliers; health care is worrying about ageing doctors and the lack of nurses. Companies are struggling to hire new workers, either to fill places vacated by those who have retired or for brand new positions as companies expand. We can expect that new jobs will be generated, but on the other hand, with decreasing unemployment and a decreasing number of economically active due to the ageing process, it will be more and more problematic. The research showed that many managers understand diversity management as synonym to antidiscrimination; it turned out that the greatest problem in our conditions is considered gender equality, especially in remuneration (46\%). In the area of equal opportunities, $31 \%$ consider the violation of this principle in terms of specific gender requirements to be the greatest problem and also the problem of employees over 50 years. In the area of reconciliation of work and family life, $32 \%$ see the problem in implementing measures in the company that enable the work and family responsibilities of women and men. In the future, the interviewees see a problem in the employment of foreigners. 14\% have experience with foreign employees. For example bank managers have good experience with foreign employees; but more problems are in manufacturing companies; diversity management is better evaluated by managers of companies with foreign participation. Concerns arise from ignorance of the issues of management diversity and the lack of competence in managing people in a multicultural environment. They see solutions in particular in the new approach of human resources management in the enterprise; however, they realize that, as a human resource management entity, every manager in a business needs to expand their diversity management competencies. They consider it necessary - through education to ensure the acquisition of global thinking for all employees and organizations, to promote the position of the human resources management unit as a strategic partner. They consider it necessary to have better orientation in current legislation in the field of diversity management in the workplace and its strict observance in everyday practice. Under this perspective, a change in management education is needed. It should be oriented less on the training of business analysts and more on preparing future managers for solving the ill-designed problems of real business practice. It is suggested that the focus of business education should move from 'simply' providing a body of domain-specific knowledge to give students the opportunity to apply that knowledge under realistic contexts which better resembling management practice and foster the development of generic competences. [18] The area of business education as well as the preparation of future managers in higher education with an emphasis on acquiring the competence of management diversity can also contribute significantly. Diversity management is also a question of occupational safety; ignoring its principles brings new risks at work and also other negative consequences. In particular, it is a protection against the risk of creating a negative brand meaning that can deter customers 
or partners from cooperating. Social responsibility is increasingly influencing brand perception by customers. [19, 20]

\subsection{Recommendations for sustainable human resources management}

All efforts of an organization for diversity management must be implemented in personnel processes and activities such as recruitment, recruitment, development and education, internal mobility promotion, keeping in touch with mothers on maternity or parental leave, flexible working employers also need to integrate diversity initiatives into the broader, long-term goals and mission of the organization. In organizational development, access to diversity must be integrated, planned, systemic and long-term. This approach to diversity is characteristically driven from top to bottom to other organizational levels and requires an initial assessment of where the organization is based on diversity and its vision and where it wants to be in the future. Differential analysis is used to create specific interventions to achieve the desired change goals. Human resources management units in international companies have to create something that can be described as a binder that will combine human resources with different experiences to work effectively. It is it can be ensured by creating cross-border work teams, centers of excellence created and located across the spectrum of the multinational enterprise. [21] We recommend explicitly articulating diversity management and equality principles and commitments in documents such as Human resources management policy; Work order; Collective agreement; OSH policy document. Managing diversity is also a competence ranked between personal and interpersonal skills. This competence emphasizes the need to realize that everything around us in the business world is becoming or is diverse. The competence is described as "The ability to treat, act and work with people fairly regardless of their nationality, race, culture, disability, age or gender. Furthermore, as a capacity to exploit this diversity and diversity in the best possible way, to promote equality in processes and opportunities for all. [22] The competencies that managers must acquire, generally, the managers of the HRM departments and other managers working in a global environment should have a global mindset, international experience, strong technical and strategic skills. It is necessary to focuse on the intercultural and interpersonal knowledge; the ability to adopt other cultures, global leadership and leadership skills for human resource management throughout the organization and its individual branches; mastering change management and diversity management. It was also learnt that leadership is one of the leading factors in bringing affirmative change in organizations. [23] It is necessary to introduce in the company the design of job positions and tasks related to them so that working conditions are equally accommodating for men and women; ensure equal pay for equal work of equal value by laying down rules. The trends of creation of new employment is essential to understand for human resource management because of the activities, policies, and practices of any organization involved in obtaining and developing the appropriate number and skill mix of employees. The ability to manage knowledge has become increasingly more crucial in today's world since knowledge is a vibrant force in the rapidly changing global economy and society. [24, 25]

\section{Conclusion}

Today, diversity management is an integral part of the human resources management strategy. Successful individuals do not form a homogeneous group: they include men and women, young and old, people of different origins, skin colors, religion, sexual orientation. Building diverse teams and respecting this personal and cultural diversity leads to success. 
Diversity management is also becoming a known term in Slovakia, which, to a greater or lesser extent, is mainly used by international companies. The workforce in today's organizations is becoming increasingly diverse, and social development affects the lives of employees and challenges many managers. Demographic change themes relate to the changing nature of the concept of the workforce, especially in our local conditions on age and population aging (age management), gender (Gender), and ethnic minorities, which are likely to create ever larger part of the workforce. Slowly and surely there are companies and organizations that carry out audits of workforce diversity, carry out regular evaluations of employees, including their satisfaction, and subsequently introduce systematic programs to support the sustainability of a skilled workforce. Building diverse teams and respecting this personal and cultural diversity leads to success. Slovak practice also shows the topicality of the issue of management diversity and the need to implement the requirements of its specifics into the everyday life of companies in the interest of sustainability of human resources management and sustainable prosperity in the current globalized environment. Further research is needed in area of diversity management especially in terms of older employees; foreign employees and gender at work in specific condition of Slovakia according to the structural development of employment by sectors because we expect next year's important occupational changes. Our analysis provides an overview about actual problems in the field of diversity management, but the further research is an opportunity to give more targeted recommendations.

\section{Acknowledgment}

This paper is an output of the Science Project No. 4/PEDAS/2019 Sustainable Human Resources Management in Era of Globalization

\section{References}

1. F. A. Joshua, Assessment of the Role and Functions of Human Resources Department in Small and Medium Scale Enterprise Companies in Ile - Ife, Osun. Journal of Human Resource Management 7 , 32-40 (2019)

2. M. E. M. Barak, Managing diversity: Toward a globally inclusive workplace. (SAGE Publications, California, 2016)

3. C. Dickie, Z. Soldan, Diversity Management. (Tilde Publishing, Prahan, 2008)

4. Act no. 5/2004 Coll. On Employment Services Act

5. K.Y. Williams, C.A. O’Reilly, Demography and Diversity in Organizations: A Review of 40 Years of Research. Research in Organizational Behavior 20, 77-140 (1998)

6. R.L. Tung, New perspectives on human resource management in a global context. Journal of World Business 51, 142-152 (2016)

7. W.B. Johnston; A. E. Packer, Workforce 2000: Work and Workers for the Twenty-First Century. (SAGE Publications, California, 1987)

8. T.H. Cox, S. Blake, S. Managing cultural diversity: Implications for organizational competitiveness. Academy of Management Executive 5, 45-56 (1991)

9. D.A. Harrison, K.J. Klein, What's the Difference? Diversity Constructs as Separation, Variety, or Disparity in Organizations. Academy of Management Journal 32, 11991228 (2007)

10. H. D. U. Indrajith, F. M. Fairoz, Impact of Management Quality and Workforce Quality on Organizational Performance: A Case Study of Sri Lanka. Journal of Human Resources Mangement. 6, 37-43 (2018)

11. J. Wrench, Diversity management and discrimination : immigrants and ethnic minorities in the EU. (Blackwell Publishing, USA, 2007) 
12. H. Tajfel, Human Groups and Social Categories. Studies in Social Psychology. (Cambridge University Press, UK, 1981)

13. E. N. Ayega, S. Muathe, Critical Review of Literature on Cultural Diversity in the Work Place and Organizational Performance. Journal of Human Resource Management 6, 9-17 (2018)

14. H. J. Aretz, K. Hansen, Erfolgreiches Management von Diversity. German Journal of Human resources Management 17, 9-36 (2003)

15. J. Kliestikova, J., A. Krizanova, T. Corejova., P. Kral, E. Spuchlakova, Subsidies to Increase Remote Pollution? Sci-Eng-Ethics 24, 755-767 (2018)

16. J. Kliestikova, K. Janoskova, Branding with understanding: how national profile of consumer influences brand value perception. Marketing and management of innovations 3, 149-157 (2017)

17. Act. No. 311/2001 Coll. Labor Code

18. A. Perusso, A comprehensive active-based learning environment for management education: an evaluative study. Proceeding of 10 th International conference of education, research and innovation (ICERI). Seville, Spain, 8187-8195 (2017)

19. K. Valaskova, J. Kliestikova, A. Krizanova, Consumer Perception of Private Label Products: An Empirical Research. Journal of Competitiveness 10, 149-163(2018)

20. Ch. Bolton, V. Machova, M. Kovacova, K. Valaskova, The Power of Human-Machine Collaboration: Artificial Intelligence, Business Automation, and the Smart Economy. Economics. Management, and Financial Markets 13, 51-56 (2018)

21. D. Briscoe, R. Schuler, I. Tarique. Policies and Practicies for Multinational Enterprises. International Human resources Management 4, (2019)

22. M.M. Lombardo, R. W. Eichner, For your improvement. A guide for development and coaching. For learners, managers, mentors and feedbacks givers. Lominger International: A guide for development and coaching. (2006)

23. H. E. Mansaray, The Role of Leadership Style in Organisational Change Management: A Literature Review. Journal of Human Resources Management 7, 18 31.(2019)

24. J.K. Basak, S. K. Chowdhury, M. Miah, Dynamics of Labour Force for Human Resource Management. IHRM 2, 1-11 (2014)

25. T. B. Bayu, An Assessment of Knowledge Sharing and Management Practices. HEI; JHRM 6, 111-118 (2018) 